\title{
Behavioural insights into housing relocation decisions: the effects of Beijing Olympics
}

Article

Accepted Version

Wang, M., Bao, H. X. H. and Lin, P.-T. (2015) Behavioural insights into housing relocation decisions: the effects of Beijing Olympics. Habitat International, 47. pp. 20-28. ISSN 01973975 doi: https://doi.org/10.1016/j.habitatint.2015.01.001 Available at https://centaur.reading.ac.uk/83476/

It is advisable to refer to the publisher's version if you intend to cite from the work. See Guidance on citing.

To link to this article DOI: http://dx.doi.org/10.1016/j.habitatint.2015.01.001

Publisher: Elsevier

All outputs in CentAUR are protected by Intellectual Property Rights law, including copyright law. Copyright and IPR is retained by the creators or other copyright holders. Terms and conditions for use of this material are defined in the End User Agreement.

www.reading.ac.uk/centaur 
Central Archive at the University of Reading

Reading's research outputs online 


\title{
Behavioural Insights into Housing Relocation Decisions: The Effects of Beijing Olympics
}

\author{
Mei Wang ${ }^{a}$, Helen $\mathrm{BaO}^{\mathrm{a},{ }^{*}}$ and Pin-Te Lin ${ }^{\mathrm{b}}$
}

${ }^{a}$ Department of Land Economy, University of Cambridge, Cambridge, UK

${ }^{\mathrm{b}}$ Research School of Finance, Actuarial Studies and Applied Statistics, Australian National University, Canberra, Australia

\begin{abstract}
This article examines the impact of mega events on Beijing housing market from a behavioural perspective. By exploring the situation surrounding the Beijing 2008 Summer Olympics, we analyse the relationship between mega-event regeneration and expected residential relocation outcomes. Our findings suggest that Beijing Olympic regeneration caused disadvantaged groups to anticipate relocation to undesirable areas, as a result of improved infrastructure, public security, and urban environment. Behavioural sciences research indicates that expectation influences decision-making by serving as a salient reference point. Agents who perceived themselves as in a disadvantaged position or holding a gloomy prospect of their future are more likely to end up in such a situation. This paper offers insights into an effect of mega event regeneration projects that has been largely overlooked in the literature, i.e., the expected housing relocation outcomes. The research calls for government intervention and public attention to this important behavioural aspect of mega-event effects.
\end{abstract}

Keywords: Anchoring, Displacement, Gentrification, Prospect Theory

*Corresponding author. E-mail: hxb20@cam.ac.uk. 


\title{
Behavioural Insights into Housing Relocation Decisions: The Effects of Beijing Olympics
}

\begin{abstract}
This article examines the impact of mega events on Beijing housing market from a behavioural perspective. By exploring the situation surrounding the Beijing 2008 Summer Olympics, we analyse the relationship between mega-event regeneration and expected residential relocation outcomes. Our findings suggest that Beijing Olympic regeneration caused disadvantaged groups to anticipate relocation to undesirable areas, as a result of improved infrastructure, public security, and urban environment. Behavioural sciences research indicates that expectation influences decision-making by serving as a salient reference point. Agents who perceived themselves as in a disadvantaged position or holding a gloomy prospect of their future are more likely to end up in such a situation. This paper offers insights into an effect of mega event regeneration projects that has been largely overlooked in the literature, i.e., the expected housing relocation outcomes. The research calls for government intervention and public attention to this important behavioural aspect of mega-event effects.
\end{abstract}

Keywords: Anchoring, Displacement, Gentrification, Prospect Theory 


\section{Introduction}

It has been generally agreed that successfully hosting mega-events, such as the Olympic Games, provides valuable opportunities in achieving city branding, attracting international investments, and creating significant and lasting economic benefits to the host city (Andranovich, Burbank, \& Heying, 2001; Hiller, 2000; Roche, 2000, 2006). Staging for mega-events often requires large sums of public funds to be spent on sports facilities, amenities and infrastructure improvements. Existing research has proved that transportation infrastructure, parks and other amenities have been capitalized into housing prices. (Ahlfeldt, 2013; Phuong \& Yinger, 2011; Wu \& Dong, 2014; Zheng, Sun, \& Wang 2014). Recently, academic researchers and public planners have given increased attention to the social impact of mega events since this has been stated to be equally as important as their economic impact (Humphreys, Johnson, Mason, \& Whitehead, 2011; Kim, Gursoy, \& Lee, 2006; Wicker, Prinz, \& Hanau, 2011). It has been found that hosting mega events provides many opportunities to increase publicity and establish a new image for the host city (Kim \& Petrick, 2005; Kim et al., 2006; Mihalik \& Simoneita, 1998; Wei \& Yu, 2006). Furthermore, success in competition creates excitement and gives a positive effect on civic pride in the host city (Kim \& Petrick, 2005; Ohmann, Jones, \& Wilkes, 2007; Ritchie, Shipway, \& Cleeve, 2009; Soutar \& McLeod, 1993). Thus, host cities can benefit significantly from staging mega-events.

However, not all previous studies have found evidence of positive economic and social impacts from sporting mega-events. Event-related construction and an influx of tourists may bring problems in using public resources and seriously affects resident satisfaction (Chalkley \& Essex, 1999; Delamere, Wankel, \& Hinch, 2001; Kim \& Petrick, 2005; Mihalik \& Simoneita, 1998; Smith, 2009; Soutar \& McLeod, 1993). Another social concern relating to staging mega events is the potential cause for an increase in noise, crime and terrorist attacks (Barker, Page, \& Meyer, 2002; Kim \& Petrick, 2005; Kim et al., 2006; Konstantaki \& Wickens, 2010; Mihalik \& Simonetta, 1998; Ritchie et al., 2009; Zhou \& Ap, 2009). More importantly, mega events are sometimes found to be reinforcing the increasing polarization of urban populations in which the wealthy and the poor have very different urban lives (Hiller, 2006; Shin, 2009; Shin \& Li, 2013). This is often a result of the urban regeneration process for staging mega events.

A mega event is the perfect companion to urban regeneration and can also serve as a catalyst for the initiation, expansion and intensification of plans for regeneration (Chalkley \& Essex, 1999). Event-led regeneration can significantly improve the appearance of existing housing stock, cause appreciation in property price and attract increasing investment in the development of new, top-end flats in the host city, particularly in the event-related area. The creation of such a 'desirable' middle-class living space as the result of event-related construction and infrastructure development is accompanied by a corresponding breakdown in community structure along ethnic lines as families and individuals are forced to relocate. The boundaries of social segregation shift but the underlying problem of social disadvantage remains, especially for lower income people (Hamnett, 2003). Therefore, the mega event facilitates the transformation of the event precinct from a working class district to a community largely inhabited by uppermiddle class residents after the major event (Hall \& Hodges, 1998; Hiller, 2006). It seems that there are 'few social benefits for those unable (or disinclined) to present themselves as consumers' (Whitson \& Horne, 2006).

Mega events are also responsible for the loss of affordable housing. It has become commonplace (such as with the Sydney Olympic Games and the Atlanta Games) that social housing promised by the government fails to be built due to the diversion of public funds towards event construction (Lenskyj, 2002). Olympic experience in developing countries is likely 
to be many times harsher for urban marginal populations, especially for migrants who have a weak foothold in the city. For example, Shin and Li (2013)'s study found that as Beijing expands and its inner-city areas are redeveloped, low-skilled migrants without the resources to access private home ownership are pushed further out to suburban areas, where affordable places such as shanty-towns are concentrated.

In conclusion, mega events can contribute to a deepening of social differences, producing new spatial distributions of wealth and well-being and causing polarization in local populations in regenerating areas. However, existing studies focus primarily on the outcomes of mega event-induced regeneration. There has been very little research examining the underlying decision processes. This 'snap-shot' approach overlooks two important aspects of relocation decision making. First of all, the decisions and implications involved in relocation should be studied according to long-term residential trajectory and by considering past residential trajectories and housing pathways (Clappham, 2002; Lelevrier, 2013; Stovel \& Bolan, 2004). Secondly, displaced residents react to regeneration context and regulations differently by adopting different choice processes and strategies (Briggs, Popkin, \& Goering, 2010; Posthumus, Bolt, \& Kempen, 2014; Posthumus \& Kleinhans, 2014). Therefore, it is important to study all stages involved in relocation decision process, and to understand how stakeholders react to regeneration programmes.

To bridge this gap in the literature, our paper aims to reveal how mega event-induced regeneration affects residents' expectation of their future housing location by focusing on the Beijing 2008 Olympic Games. This approach focuses on the very early stage of the decision making process and considers the behavioral and psychological aspect of relocation decisions. More specifically, we interviewed residents before they were relocated and we studied the relationship between perceived Olympic regeneration benefits and expected relocation outcomes. In behavior sciences, experiment and field evidences generally support the existence of an anchoring effect, where decisions are made dependent of a salient reference point (See, for example, Barberis, 2013; DellaVigna, 2009; Kahneman \& Tversky, 1979; Seiler, Seiler, \& Lane, 2012). Hence, it is important to analyse the significant force of influencing our reference point (Ericson \& Fuerst, 2011).

It has been established that residents who perceived themselves to be worse-off will make myopic decisions (Liu, Feng, Suo, Lee, \& Li, 2012) and also that perceived inferior social status has an adverse impact on real estate decision-making (Tower-Richardi, Brunye, Gagnon, Mahoney, \& Taylor, 2014). Residents who expected loss in future decisions are more likely to end up in the 'loss domain' (Bilgin, 2012). Consequently, residents who anticipated moving to an undesirable location are more likely to be 'forced out' from the gentrified areas. Our research established the causal relationship between perceived Olympic impact and anticipated relocation outcomes. On the one hand, mega events enhance the quality of life by improving infrastructure, public security and the environment. On the other hand, the same effect caused the disadvantaged group (i.e., tenants in our study) to hold gloomy expectations towards their future housing location choices. The effect is robust among different model specifications, when demographic and socio-economic characteristics, as well as regional heterogeneity are controlled.

The remainder of this paper proceeds as follows. Section 2 gives the institutional background of this study by defining and discussing the areas affected by the Olympic Games. Section 3 presents survey design and data collection processes. Section 4 provides empirical findings, and Section 5 gives conclusions and policy implications. 


\section{The 2008 Beijing Olympic Games}

Although most of the Olympic facilities are located in only two of the 16 districts in Beijing, the impact of the Olympic Games reached further beyond these areas. As shown in Fig. 1, the 16 districts in Beijing are classified into four functional regions as follows. The 'City Core' region is where the central government and financial institutions are located. This region includes the Dongcheng and Xicheng districts. The 'City Extension' area includes four districts Chaoyang, Haidian, Shijinghan, and Fengtai. This region is the home of most of the higher education institutions and high-tech companies. The 'New Development' region (consisting of Fangshan, Tongzhou, Shunyi, Changping, and Daxing district) and the 'Conservation' region (consisting of Mentougou, Huairou, Pinggu, Miyun, and Yanqing district) are relatively less developed, and subsequently regarded as the suburban areas of Beijing. Some key economic and social indicators of these districts are given in Table 1. The two urban areas (i.e., City Core and City Extension) are more densely populated and have a higher average salary.

Fig. 1. Functional Regions in Beijing

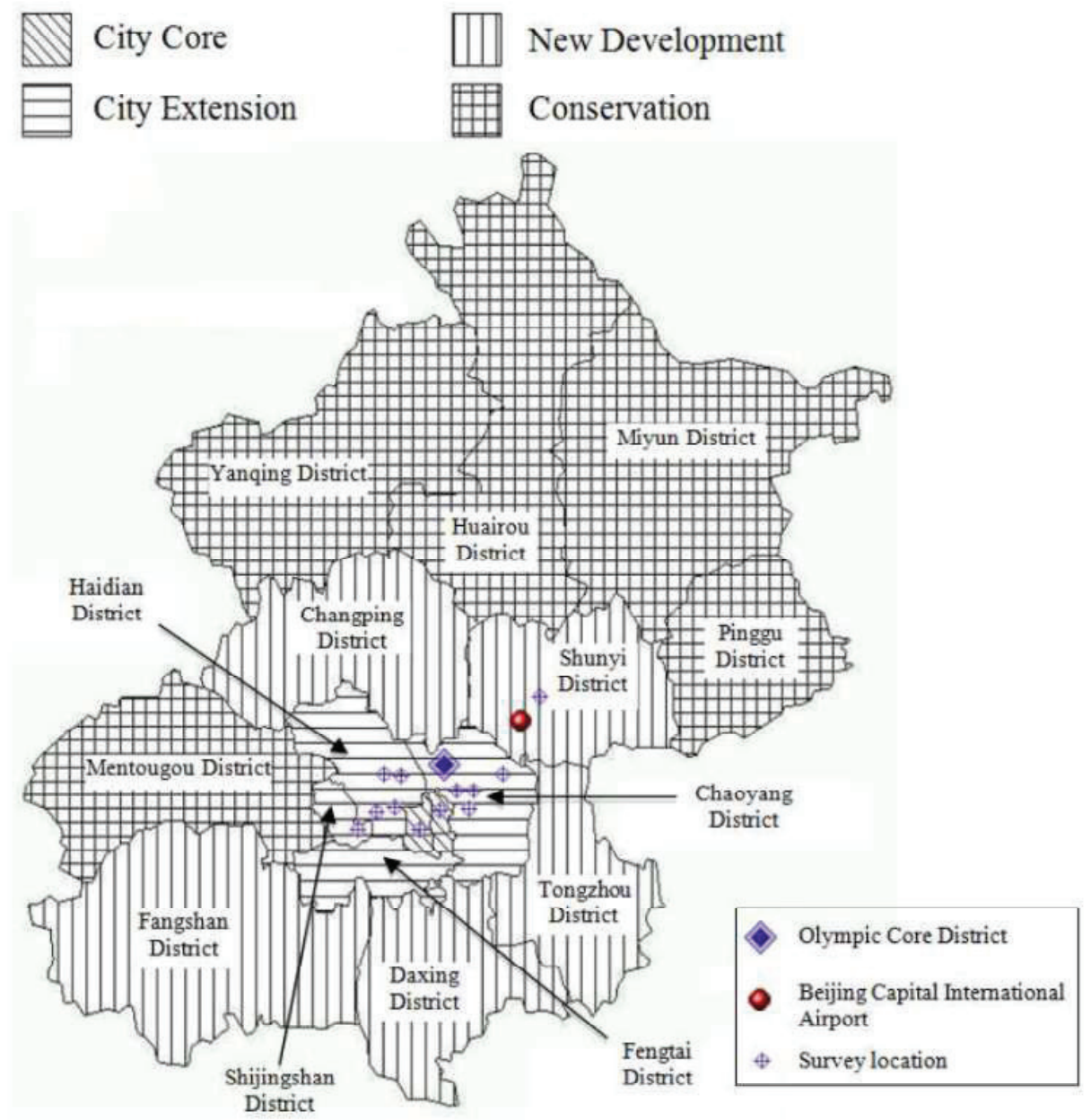


Table 1

Social and economic statistics by districts (2012)

\begin{tabular}{|c|c|c|c|c|}
\hline & $\begin{array}{l}\text { Population } \\
\text { (in 10,000) }\end{array}$ & $\begin{array}{c}\text { Area } \\
\left(\text { in } \mathrm{km}^{2}\right)\end{array}$ & $\begin{array}{c}\text { Population } \\
\text { Density } \\
\text { (person } / \mathrm{km}^{2} \text { ) }\end{array}$ & $\begin{array}{l}\text { Average Salary } \\
\text { (CNY per year) }\end{array}$ \\
\hline Beijing & 2069.3 & 16410.54 & 1261 & 85307 \\
\hline \multicolumn{5}{|l|}{ City Core } \\
\hline Dongcheng & 90.8 & 41.86 & 21691 & 97531 \\
\hline Xicheng & 128.7 & 50.53 & 25470 & 120861 \\
\hline \multicolumn{5}{|c|}{ City Extension } \\
\hline Chaoyang & 374.5 & 455.08 & 8229 & 93619 \\
\hline Fengtai & 221.4 & 305.80 & 7240 & 58276 \\
\hline Shijingshan & 63.9 & 84.32 & 7578 & 65300 \\
\hline Haidian & 348.4 & 430.73 & 8089 & 97488 \\
\hline \multicolumn{5}{|c|}{ New Development } \\
\hline Fangshan & 98.6 & 1989.54 & 496 & 55023 \\
\hline Tongzhou & 129.1 & 906.28 & 1425 & 52902 \\
\hline Shunyi & 95.3 & 1019.89 & 934 & 69728 \\
\hline Changping & 183.0 & 1343.54 & 1362 & 63027 \\
\hline Daxing & 147.0 & 1036.32 & 1418 & 71221 \\
\hline \multicolumn{5}{|c|}{ Conservation Development } \\
\hline Mentougou & 29.8 & 1450.70 & 205 & 60111 \\
\hline Huairou & 37.7 & 2122.62 & 178 & 58090 \\
\hline Pinggu & 42.0 & 950.13 & 442 & 45061 \\
\hline Miyun & 47.4 & 2229.45 & 213 & 52762 \\
\hline Yanqing & 31.7 & 1993.75 & 159 & 45820 \\
\hline
\end{tabular}

Since Beijing won the bid for the Summer Olympic Games in 2001, over 300 billion CNY (around 48.9 billion USD) was invested in the preparation for the event between 2002 and 2008. The Olympic Core District (the yellow area in Fig. 2) was designated as a recreational centre where new sporting venues and a National Park were to be connected by 62 roads and four flyovers. The construction of sport facilities and infrastructure upgrades were not limited to the Olympic Core District, but spread throughout Haidian and Chaoyang districts, as indicated by the red dots in Fig. 2 .

China's government reportedly drew up a budget of 21.7 billion USD for 142 Olympicsrelated projects in Beijing since 2001. The unprecedented investment in infrastructure, especially the transportation network, not only improved the accessibility to the Olympic Core District but also to the city centre and the Beijing Capital International Airport. For example, a total of four new subway lines were developed throughout the City Core area; a new line was built to connect the international airport with the rest of the city (See Fig. 3). In addition to the direct investment in event venues, the government spent a further 40 billion USD on infrastructure, of which 26 billion USD were contributed to transportation and the rest were used to improve the energy network, water and sewage systems and the urban environment ${ }^{1}$. The master plan of this ambitious project is summarized in the City Regeneration and Beautification (CRB) programme. This programme was designed to reinvent Beijing's image as a cultural metropolis with a dynamic economy and liveable space. The government's determination to create this new image

${ }^{1}$ Beijing Organising Committee for the Games of the XXIX Olympiad (http://www.beijing2008.cn). 
of Beijing is reflected in the official slogan of the 2008 Games: "New Beijing, Great Olympics" The city has experienced fundamental physical transformation as a part of the Olympic development process.

Fig. 2. Distribution of Olympic venues

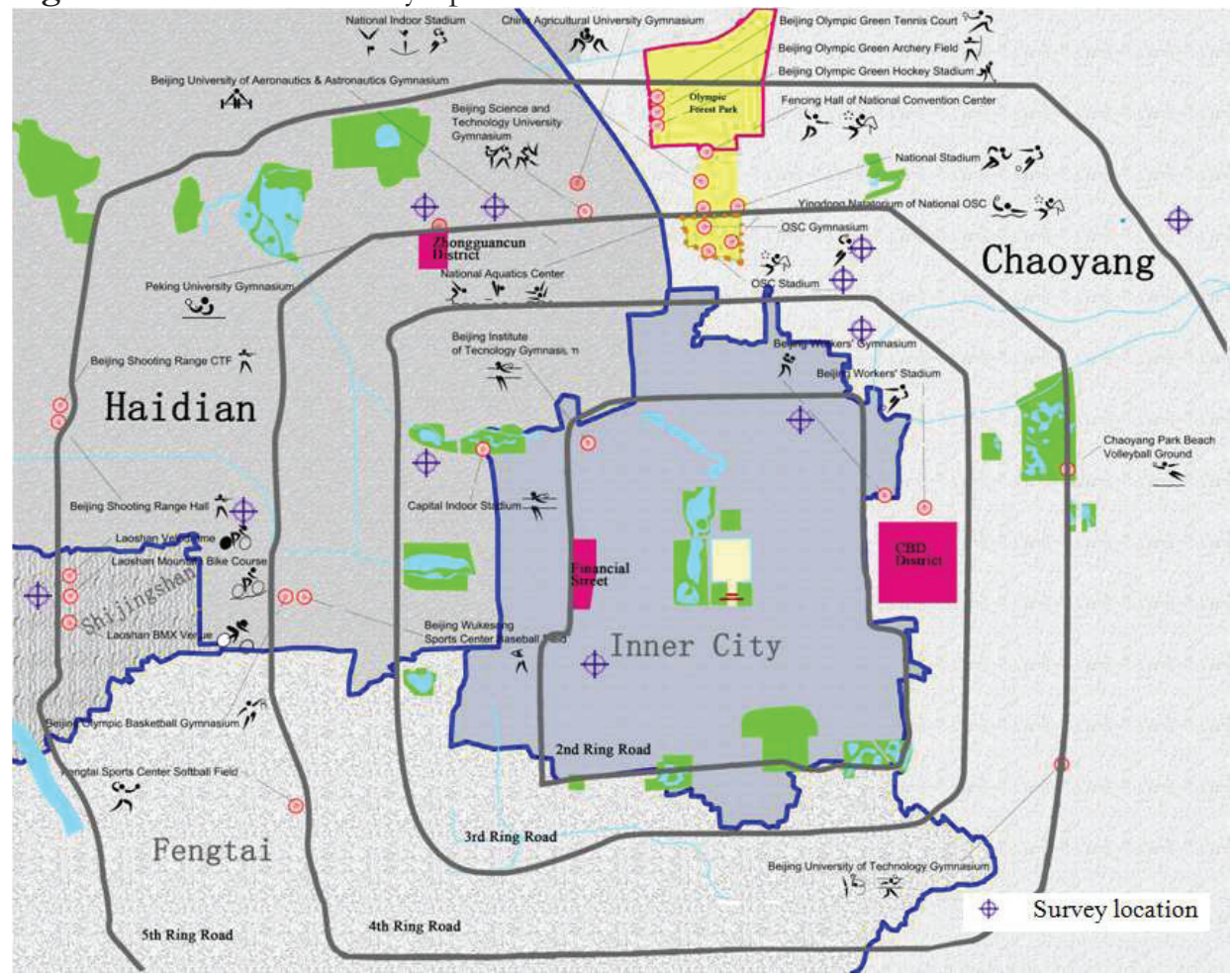

Source: Adapted from http:// commons.wikimedia.org/wiki/File:Beijing_2008_olympic_venue.svg

Fig. 3. Beijing underground network (2002 vs. 2008)

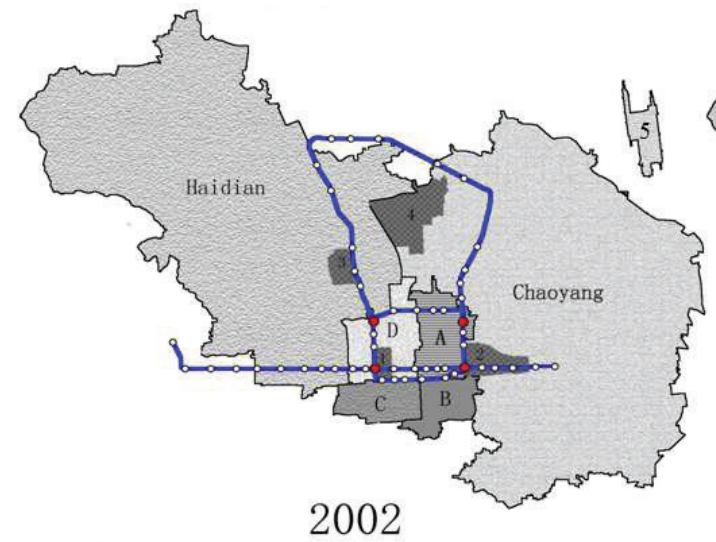

A: Dongcheng District

B: Chongwen District (merged into Dongcheng District in 2010)

C: Xuanwu District (merged into Xicheng District in 2010)

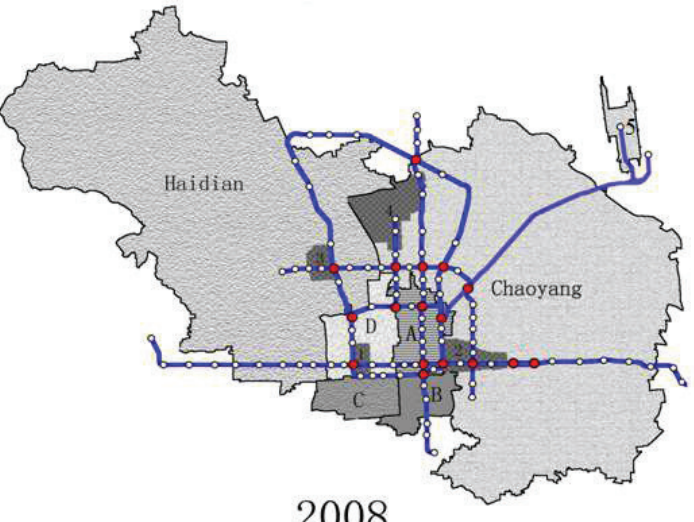

D: Xicheng District

1: Financial Street

2: Central Business District

3: Zhongguancun

4: Olympic Park

5: Beijing Capital International Airport 
The CRB programme was designed to improve the physical environment and the functionality of different regions based on their existing infrastructure, economic condition and social structure. The City Core is a densely populated area with well-developed infrastructure. It is also renowned for its economic prosperity and political significance. Thus, the objective of the $\mathrm{CRB}$ programme in this area was to improve existing infrastructures while preserving the traditional neighbourhood and social structure. This is in contrast to the regeneration target and process implemented in the host regions - the Haidian and Chaoyang districts.

The Haidian and Chaoyang districts are relatively less populated and less economically active than the two City Core districts (See Table 1). Consequently the CRB programme for these districts was mainly manifested in the construction of new event venues, transportation networks and landscaping. An investment of 36 billion CNY (about 5.9 billion USD) was made for the upgrading of public transportation infrastructures, including the construction of the Sixth Ring Road, ten expressways, seven subway lines and the expansion of Beijing Capital International Airport. The CRB programme also emphasised the social and cultural development in this area by constructing dozens of new museums, libraries, and public spaces. Twenty-five historical sites were also identified as preservation zones.

As the main functioning area, the Olympic Core District was allocated on the border between the Haidian and Chaoyang districts. Historically, Haidian district has been the academic headquarters of Beijing, where the nation's top universities are concentrated. The district is also the home of Zhongguancun, the first high-tech cluster in China. This district develops along a trajectory characterized by increasing social and economic segregation. South Haidian, where Zhongguancun and the academic institutions are located, is equipped with higher quality infrastructure and cultural amenities. The north remained primarily rural and had been occupied by an agricultural population residing in scattered villages until the early 2000s. Similarly, Chaoyang district was a swath of farmland just over two decades ago. Starting from 1993, the establishment and development of the Central Business District (CBD) in this district prompted the improvement of its transportation network and public amenities. However, prosperity was limited to the $\mathrm{CBD}$ and its neighbouring district only, whist the infrastructure and services remained less accessible than in other locations.

In this study, we define Olympic affected areas as the districts that hosted event venues or received significant attention in the CRB programme. This includes five urban districts (i.e., Dongcheng, Xicheng, Chaoyang, Haidian and Shijingshan districts) and one suburban district (Shunyi district). As shown in Fig. 2, most of the Olympic venues are located in Chaoyang, Haidian and Shijingshan district. Shunyi district mainly hosted water sports venues, but the expansion of the international airport and the construction of the new subway line to the airport greatly improved the accessibility to this district. Although the two City Core districts did not host many event venues, the CRB programme allocated a significant amount of funding to improve the natural, social, and cultural environment in these districts. Subsequently, these districts were selected as the study areas. We then conducted survey interviews in these districts to investigate if and how Olympic regeneration affected residential displacement. 


\section{Survey design and implementation}

As there is a lack of official statistics regarding displacement and gentrification in China, we collected and constructed our dataset through survey interviews. The survey was conducted in 2009, one year after the Olympic Games, when the event impacts had taken effect and residents' enthusiasm remained strong. In-person interviews directly investigate whether or not the respondents are displaced by examining whether their home-purchase plan has changed in terms of location before and after the mega event. By doing so, the risk of selection bias ${ }^{2}$ can be reduced.

To strike a balance between sample representativeness and survey cost, we adopted a stratified sampling procedure as follows. We used the six districts as strata and performed systematic sampling to randomly select residential developments from each strata/district. This resulted in 12 residential developments as our survey locations (marked by blue crosses in Fig. 1 and Fig. 2). Next, we randomly selected households in each survey location to conduct the interviews. In China, residential properties are typically developed as clusters of high-raise buildings, surrounded by a wide range of amenities. In this sense, each development can be viewed as a small yet well-established community. The number of residents in each residential development varies from hundreds to thousands. More importantly, the social and economic background in these housing developments is often representative of its neighborhood ${ }^{3}$.

The survey were designed and monitored by the authors, and implemented by a welltrained team from the State-owned Assets Supervision and Administration Committee ${ }^{4}$. A total of 880 face-to-face interviews were carried out with a response rate of $67 \%$ (or 589 complete interviews). The questionnaire consists of three parts - Home Purchase Plan, Olympic Impact, and General information (demographic and socio-economic information).

In the Home Purchase Plan part, the respondent was asked if he or she is a homeowner or tenant. Identified tenants were then asked 1) when and where they will purchase a home; 2) whether or not the location of their targeted flat is in accordance with their original plan; 3) if it has to be different from their plan; 4) whether the location is better or inferior than the respondent's plan. These questions were used jointly to determine whether a respondent will be relocated involuntarily to an undesirable location. More specifically, if a tenant's answer to question 4) is 'Yes', the observation will be classified as involuntary relocation. Question 1) through Question 3) were not used in generating the involuntary relocation variable, but for cross-validation (i.e., we kept questionnaires where answers to all four questions are consistent).

\footnotetext{
${ }^{2}$ Despite its wide use, the reliability of census data is often questioned in relation to selection bias, as it defines 'displacement' by using turnover (mobility) rate of low-income households in gentrified neighbourhoods at one point in time. As Newman and Wyly (2006) questioned, "Can we understand displacement if we measure it only as a snapshot in time?" They further suggested that measuring displacement in the heart of gentrified neighbourhoods in the late 1990s creates considerable selection bias: after two generations of intense gentrification, any low- and moderate-income renters who had managed to avoid displacement are likely to be those people who have found ways to adapt and survive (under a combination of regulatory protection and individual sacrifice or creativity) in an increasingly competitive housing market.

${ }^{3}$ Top-end, luxury development projects were excluded due to lack of representativeness. The rest of the developments were all large scale (consisting of more than 500 housing units) and had residents from various backgrounds.

${ }^{4}$ The State-owned Assets Supervision and Administration Committee (SASAC) is a government institution that oversees the management and operation of all state-owned assets in China. As most of the housing developments are effectively owned and/or managed by state-owned companies, we worked with the SASAC in order to gain access to these residential developments. More importantly, the SASAC has its own research department that conducts surveys regularly in Beijing. The experience and skills of their survey team were essential to ensure the effective implementation of our survey.
} 
In the Olympic Impact part, the respondent was asked about their perceptions of the impact of the Olympics on their current residence and Beijing's housing market as a whole. The Olympic impact was assessed in the areas of infrastructure, public security, amenities and environment. Respondents were asked to rank the improvement in each of the four areas from 0 (significantly deteriorated) to 10 (significantly improved).

In the final part of the questionnaire, we collected information on demographic and socio-economic information. This information was used in our model to isolate the net effect of Olympic regeneration on relocation decisions. Moreover, it is also helpful to verify if our sample is representative of the population. In Table 2, the distribution of sample points among districts and some descriptive statistics are given. A full list of variable definitions can be found in Table 3. In general, the background of our respondents is similar to the statistics given in Table 1. For example, respondents' education level in Chaoyang and Haidian districts is higher than other districts. Moreover, there is a reasonable variation among respondents' backgrounds for all variables and across all districts. Overall, the quality and quantity of the survey data is satisfactory. 


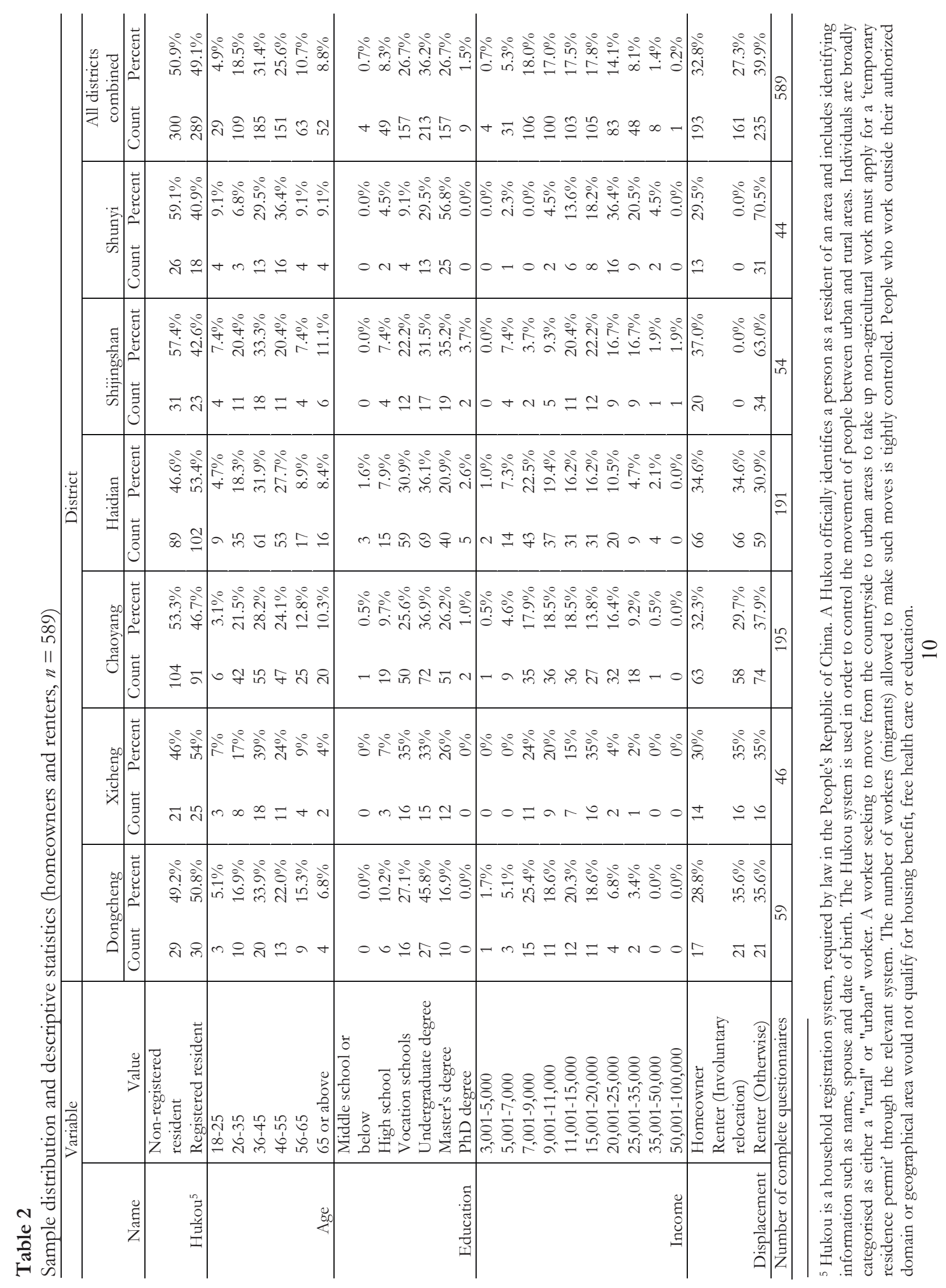




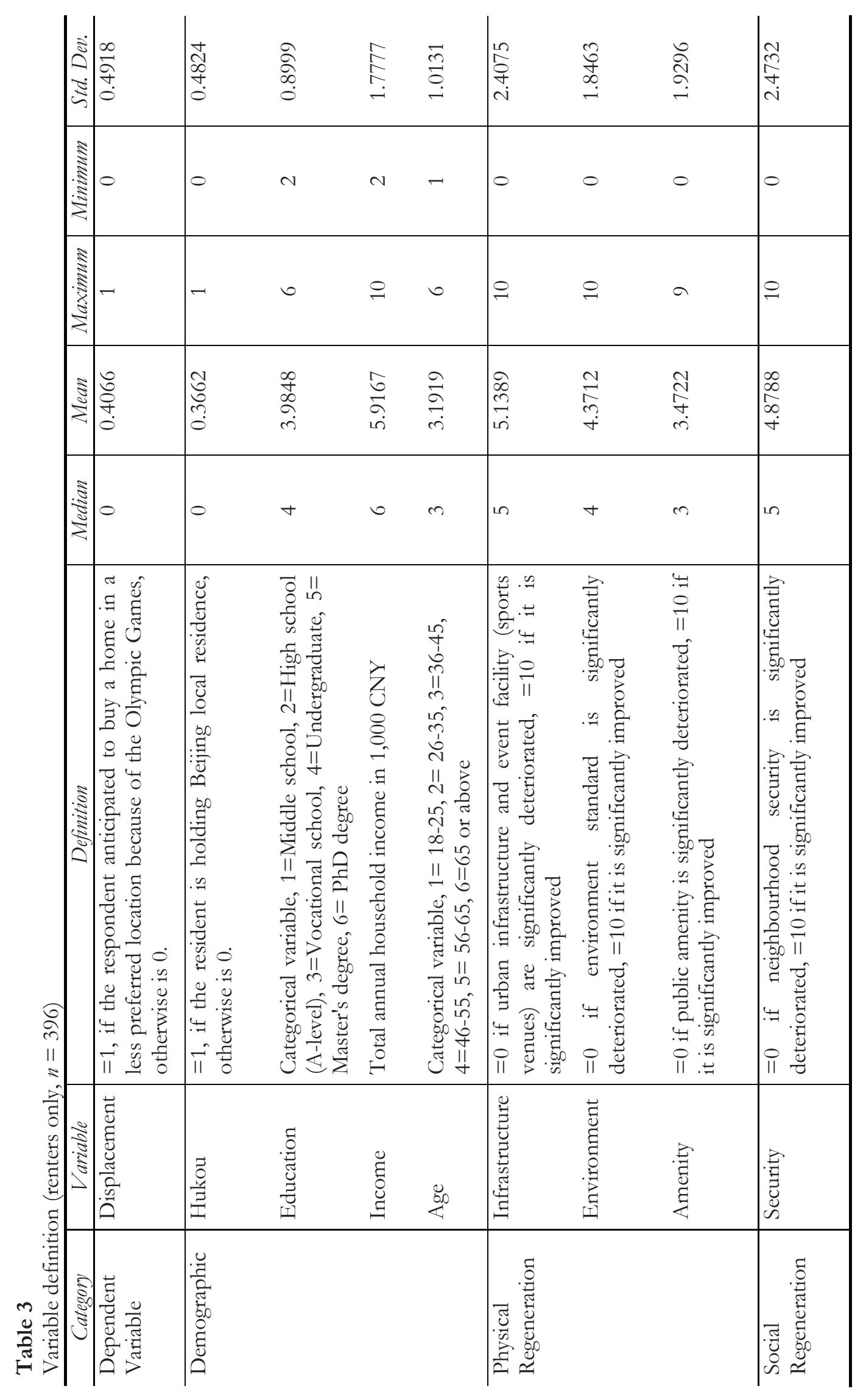




\section{Model specification and empirical results}

Our empirical model is based on Freeman and Braconi (2004)'s framework, where involuntary displacement is a function of residents' characteristics and regeneration effects. Specifically, it examines if the impacts of event regeneration such as improved neighbourhood security, public amenities and transport infrastructure are related to forced relocation. The relationship can be described using Eq. (1).

$$
I D=f(D, P, S)
$$

where ID (Involuntary Displacement) is the respondent's choice of whether they will involuntarily buy a home in a less favourable location because of the mega-event regeneration, $D$ (Demographic) is the respondent demographic characteristics, $P$ (Physical regeneration) represents impacts of event physical regeneration such as infrastructure development, public amenities, and environmental quality, and $S$ (Social regeneration) captures impacts of event social regeneration including neighbourhood security.

We modified this base model in two aspects. Firstly, the dependent variable is not observed but perceived relocation outcomes. This is denoted as Displacement in Table 3 and Eq. (2) below. Secondly, the model was estimated using renters' data only. Homeowners in these Olympic affected areas are benefiters of Olympic regeneration, and are unlikely to want to move to other areas. For them, involuntary relocation is not necessarily relevant because they don't have to move. Tenants, on the other hand, will have to make a location choice sooner or later. Olympic regeneration effects, if any, will manifest themselves in their relocation decisions. More importantly, recent statistics shows that in 2012 over $70 \%$ of the residential property transactions were first-time home purchases in China ${ }^{6}$. Our sample also shows similar patterns where about $32.8 \%$ of the respondents were homeowners (See Table 2) and no homeowners planned to purchase their next home in an inferior location. Therefore, we chose to use only renters to estimate the following equation ${ }^{7}$.

$$
\begin{aligned}
\text { Displacement }= & \beta_{0}+\beta_{1} \text { Hukou }+\beta_{2} \text { Education }+\beta_{3} \text { Income }+\beta_{4} \text { Age }+\beta_{5} \text { Infrastructure } \\
& +\beta_{6} \text { Environment }+\beta_{7} \text { Amenity }+\beta_{8} \text { Security }+\varepsilon
\end{aligned}
$$

Since the dependent variable is discrete, we estimated Eq. (2) using a logistic regression method with five different specifications (see Table 4). Model 1 is the baseline model, where all variables were entered into the model in their original form. Apparently, both Age and Amenity are insignificant. Model 2 is obtained after omitting these two variables. To further improve model fitting, variables Income and Education were transformed into either a single dummy or groups of dummy variables and included in Model 3 and Model 4 respectively ${ }^{8}$. Finally, we added district dummy variables and obtained Model 5 . Overall coefficient estimates are very robust among different model specifications. Our discussions below are based on Model 5 because it fits the data the best (its McFadden R-squared is the highest among the five models).

First of all, our survey confirmed findings in existing literature (e.g., Freeman \& Braconi, 2004; Newman \& Wyly, 2006). Generally speaking, the tenants who currently live in the area affected by the Olympics and have a lower level of education and/or income are more likely to anticipate indirect displacement caused by the Olympic Games. On the other hand, those who

\footnotetext{
${ }^{6}$ China Index Academy (http://www.fang.com/news/zt/201204/diaocha2012.html).

7 Although a homebuyer subsample was not used in the analysis, the observations were included in Table 1 to facilitate comparison.

${ }^{8}$ Groups that were insignificant at the $10 \%$ level were excluded from the models.
} 
are characterized as well-educated, high-income professionals are likely to stay in the area affected by the Olympics and will benefit from infrastructure development, environmental beautification and a secure neighbourhood. The combined effect will be gentrification and widened social and economic gaps within the city.

Our findings also suggest that having Hukou registration plays an important role in determining if the respondent will anticipate undesirable relocation outcomes. If the respondent is a local resident, then he or she has a lower chance of choosing an inferior location. This might be explained by the fact that local residents enjoy access to the housing provision fund and social housing benefits which help local citizens to secure a decent location for accommodation. However, non-registered resident such as migrant workers are not included in these housing subsidy systems.

After controlling for other determinants of relocation decisions that have been identified in the literature, Model 5 examines whether the respondent plans to move to a less preferred location in relation to infrastructure developments, environmental upgrades and improvements to public security. Among the four regeneration effect variables, Amenity is the only variable that is insignificant across all model specifications. This variable is subsequently dropped in Model 2 through Model 5. In fact, the result is not surprising though. The Olympic regeneration program put great emphasis on infrastructure, environment and security. These objects are often achieved by improving 'hardware' of the city such as building more roads and putting in more police forces. Amenity (such as quality of schools), on the other hand, is often upgraded through services improvement, which cannot be achieved in the short run. Consequently, this is an area that had not received sufficient support and attention in regeneration programs. This is also evident in Table 3, where the average score of Amenity is below 5. This suggests that respondents actually perceived negative impact from Olympic regeneration on local amenities. One of many possible reasons is that improvement in education and health care facilities was outpaced by the increase of population in the Olympic affect areas, because the majority of the Olympic regeneration funding was directed to sport venue construction and upgrades. As respondents did not experience regeneration benefits in this area, its impact on relocation expectation is not established.

Except for Amenity, all other Olympic regeneration effects have significant and positive coefficient estimates. The greater the perceived benefits of Olympic regeneration, the higher the possibility of the respondent to anticipate undesirable location choices for their future home purchase plans. Note that the effect is significant after controlling for income and education effects, and that the relationship is stable among different model specification (i.e., Model 1 through Model 5). Since the interviews were conducted in Olympic affected areas, scores of regeneration effects (i.e., values of Infrastructure, Environment, and Security) are reliable assessments by respondents who had experienced the impact of the event first-hand. The positive coefficient estimates of regeneration effects is a reflection of the anxiousness and pressure felt by the affected household, who were painfully aware of the downside of mega event-induced improvement in their neighbourhood.

This robust finding highlights the importance of understanding the behavioural and psychological aspects of mega-event regeneration. Our findings show that a positive impression of Olympic Games regeneration leads to gloomy expectations of future housing location outcomes. According to findings in behavioural sciences, respondents who perceived themselves as the 'disadvantaged' were more likely to make suboptimal or irrational housing decisions. It is important to conduct further research to gain understanding of this behavioural impact of mega event-induced regeneration. 


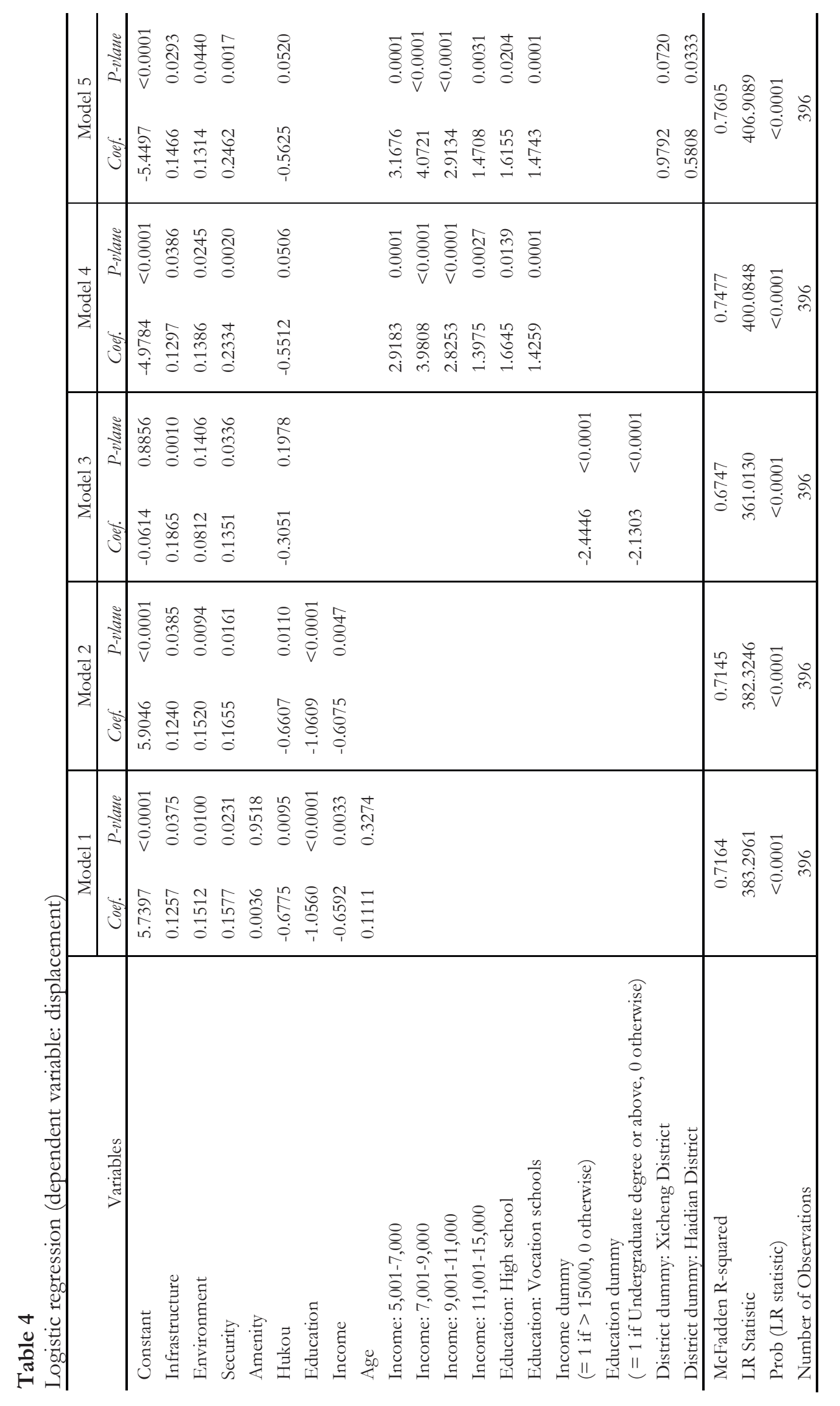




\section{Conclusions and recommendations}

Our findings support the conclusion offered by prior literature (Hall \& Hodges, 1998; Olds, 1998; Pillay \& Bass, 2008) that state-sponsored regeneration leads to landscape improvement and social upgrade, yet is often accompanied by residential displacement and social marginalisation. This finding confirms the notion that the poor suffer disproportionately from eviction and from the event regeneration which is accompanied by the loss of affordable homes (Hiller, 1998; Horne \& Manzenreiter, 2006). Our study complements not only the prior research of mega events (Greene, 2003; Hiller, 1998; Horne \& Manzenreiter, 2006; Olds, 1998; Smith, 2009, 2012; Smith \& Fox, 2007) but also contributes to current literature by further providing first-hand evidence on Beijing housing transitions (Gao \& Asami, 2011; Shin, 2009; Shin \& Li, 2013; Yu \& Cai, 2013).

Our paper confirms that Olympic regeneration has a double-edged effect. While significantly improving homeowners' welfare, tenants' perception of future housing location choice worsens as infrastructure, security, and environment improves in the host city. According to findings in psychology, neuroscience, and behavioural economics, expectation influences decision-making significantly by serving as a salient anchor point. This is essentially the 'default' option in future housing location choices. Based on Prospect Theory, this subtle 'framing effect' will lead to a greater proportion of residents to be displaced to undesirable locations. Therefore, the effects of Olympic regeneration could lead to gentrification by 'nudging' disadvantaged residents into making suboptimal (or irrational) housing decisions.

Although our study used the 2008 Beijing Summer Olympic Games as the institutional setting, the findings have greater applicability beyond Beijing and sport events. For example, our findings have significant implications for the first urbanization plan in China. On the one hand, disadvantaged groups anticipated to be displaced to undesirable locations. On the other hand, provisions of housing (i.e., social housing) can neither match the demand nor meet the standard. More specifically, due to the misalignment of goals between central and local government, social housing units are in short supply, and predominantly located in remote areas (Zou, 2014). This can only aggravate the situation. The New Urbanization Plan (2014-2020) set out some ambitious goals such as increasing urban population to be $60 \%$ by 2020 . The plan echoes the findings in the literature and in this study by aiming to improve Hukou registration significantly during this urbanization process. This will alleviate displacement effects. On the other hand, there has not been any measurement taken to counter the psychological effect on anticipated displacement by addressing the psychological impacts from mega events. This is particularly important for first tier Chinese cities such as Beijing and Shanghai, where national and international events are held regularly. The cumulative effect can have a profound impact on residents' housing decisions and, in the long run, on social belongings and lifetime satisfaction.

For future research, there are two important questions to be answered. Firstly, although the link between expectation and decision have been well established in other disciplines, the verification of this causal relationship in housing decisions has yet to be done. This is challenging in the context of China because such an empirical study requires panel data in order to follow subsequent housing location choices. However, given that the target respondents are a 'floating population' which tends to reside temporarily in one location and then relocate to an unpredictable location, panel survey data is difficult to obtain. Secondly, and more importantly, what should be done to alleviate or eliminate this anticipated displacement effect? Ideas from behavioural sciences could be borrowed in this regard. For example, the Behavioural Insight Unit (BIU) in the UK is a good example of leveraging behavioural research findings to improve the effectiveness of public policies. Working closely with the UK government, the BIU has 
successfully implemented many behavioural insights in the public administration domain, such as pension enrolment, income tax payment, and organ donation. The behavioural interventions by BIU are surprisingly effective and efficient. If sufficient understanding of behavioural aspects in relocation decision-making processes can be gained through future research, much can be done to design policies that can encourage people to make better choices for themselves and for society. 


\section{References}

Ahlfeldt, G. M., 2013. If we build it, will they pay? Predicting property price effects of transport innovations. Environment and Planning A, 45, 1977-1994.

Andranovich, G, Burbank, M. J. \& Heying, C. H. (2001). Olympic cities: Lessons learned from mega-event politics, 23, 113-131.

Barberis, N. C., 2013. Thirty years of prospect theory in economics: A review and assessment. Journal of Economic Perspectives, 27, 173-195.

Barker, M., Page, S., \& D. Meyer. (2002). Modelling tourism crime, the 2000 America's Cup. Annals of Tourism Research, 29, 762-782.

Bilgin, B. (2012). Losses loom more likely than gains: Propensity to imagine losses increases their subjective probability. Organizational Behavior and Human Decision Processes, 118, 203-215.

Briggs, X., Popkin, S. J., \& Goering, J. (2010). Moving to opportunity: The story of an American experiment to fight ghetto poverty. New York: Oxford University Press.

Chalkley, B., \& Essex, S. (1999). Urban development trough hosting international events: a history of the Olympic Games. Planning Perspectives, 14, 369-394.

Clapham, D. (2002). Housing pathways: A post-modern analytical framework, Housing, Theory and Society, 19, 57-68.

Delamere, T. A., Wankel, L. M., \& Hinch, T. D. (2001). Development of a scale to measure resident attitudes toward the social impacts of community festivals, part II: Item generation and purification of the measure. Event Management, 7, 11-24.

DellaVigna, S. (2009). Psychology and economics: Evidence from the field. Journal of Economic Literature, 47, 315-372.

Ericson, K. M. M. \& Fuerst, A. (2011). Expectations as endowments: Evidence on reference-dependent preferences from exchange and valuation experiments. Quarterly Journal of Economics, 126, 1879-1907.

Freeman, L., \& Braconi, F. (2004). Gentrification and displacement: New York City in the 1990s. Journal of the American Planning Association, 70, 39-52.

Gao, X. \& Asami, Y. (2011). Preferential size of housing in Beijing. Habitat International, $35,206-213$.

Greene, S. J. (2003). Staged cities: mega-events, slum clearance, and global capital, Downloadable at: http://www.law.yale.edu/documents/pdf/LawJournals/greene.pdf.

Hall, C. M. \& Hodges, J. (1998). 'The Politics of Place and Identity in the Sydney 2000 Olympics: Sharing the Spirit of Corporatism.' In Sport, Culture and Identity (Roche, M. (ed.)). Meyer and Meyer Verlag, Aachen,

Hamnett, C. (2003). Gentrification and the middle class remaking of Inner London, Urban Studies, 40, 2401-2426.

Hiller, H. H. (1998). Assessing the impact of mega-events: A linkage model. Current Issues in Tourism, 1, 47-57.

Hiller, H. H. (2000). Mega-events, urban boosterism and growth strategies: an analysis of the objectives and legitimations of the Cape Town 2004 Olympic Bid. International Journal of Urban and Regional Research, 24, 439-458.

Hiller, H. H. (2006). Post-event outcomes and the post-modern turn: the Olympics and urban transformations. European Sport Management Quarterly, 6, 317-332.

Horne, J. \& Manzenreiter, W. 2006, (Eds.), Sports mega-events: social scientific analyses of a global phenomenon. Blackwell/The Sociological Review: Malden, USA.

Humphreys, B. R., Johnson, B. K., Mason, D. S., \& Whitehead, J. C .(2011) 'Estimating the value of medal success at the 2010 Winter Olympic Games.' University of Alberta, Faculty of Art, Deparment of Economics, Working Paper No. 2011-20. Available at: http://www.economics.ualberta.ca/ /media/economics/FacultyAndStaff/WPs/WP20 11-20-Humphreys.pdf. 
Kahneman, D., Tversky, A., 1979. Prospect theory-Analysis of decision under risk. Econometrica, 47, 263-291.

Kim, S. S., \& Petrick, J. F. (2005). Residents' perceptions on impacts of the FIFA2002 World Cup: the case of Seoul as a host city. Tourism Management, 26, 25-38.

Kim, H. J., Gursoy, D., \& Lee, S. (2006). The impact of the 2002 world cup on South Korea: comparisons of pre- and post-games. Tourism Management, 27, 86-96.

Konstantaki, M., \& Wickens, E. (2010). Residents perceptions of environmental and security issues at the 2012 London Olympic Games. Journal of Sport and Tourism, 15, 337-357.

Lenskyj, H. J. (2002). The Best Olympics Ever? Social Impacts of Sydney 2000. Albany: State University of New York Press.

Lelevrier, C. (2013). Forced relocation in France: How residential trajectories affect individual experiences. Housing Studies, 28, 253-271.

Liu, L., Feng, T., Suo, T., Lee, K. \& Li, H. (2012). Adapting to the destitute situations: Poverty cues lead to short-term choice. PLOS ONE, 7: e33950.doi:10.1371/journal.pone.0033950.

Mihalik, B., \& L. Simoneita (1998). Resident perceptions of the 1996 Summer Olympic Games: Year II. Festival Management and Event Tourism, 5, 9-19.

Newman, K., \& Wyly, E. K. (2006). The right to stay put, revisited: gentrification and resistance to displacement in New York City. Urban Studies, 43, 23-57.

Ohmann, S. Jones, I., \& Wilkes, K (2007). The perceived social impacts of the 2006 Football World Cup on Munich residents. Journal of Sport and Tourism, 11, 129-152.

Olds, K. (1998). Urban mega-events, evictions and housing rights: the Canadian case. Current Issues in Tourism, 1, 2-46.

Pillay, U., \& Bass, O. (2008). Mega-events as a response to poverty reduction: the 2010 FIFA World Cup and its urban development implications. Urban Forum, 19, 329-346.

Phuong, N.H., Yinger, J., 2011. The capitalization of school quality into house values: A review, Journal of Housing Economics, 20, 30-48.

Posthumus, H., Bolt, G. \& van Kempen, R. (2014). Victims or victors? The effects of forced relocationson housing satisfaction in Dutch cities, Journal of Urban Affairs, 36, 13-32.

Posthumus, H., \& Kleinhans, R. (2014). Choice within limits: how the institutional context of forced relocation affects tenants' housing searches and choice strategies. Journal of Housing and the Built Environment, 29, 105-122.

Roche, M. (2000) Mega-Events and Modernity. Olympics and Expos in the Growth of Global Culture. London: Routledge.

Roche, M. (2006). Mega-events and modernity revisited: Globalization and the case of the Olympics. Sociological Review, 54, 25-40.

Ritchie, B. W., Shipway, R., \& Cleeve, B. (2009). Resident perceptions of mega-sporting events: a non-host city perspective of the 2012 London Olympic Games. Journal of Sport and Tourism, 14, 143-167.

Seiler, M. J., Seiler, V. L., \& M. A. Lane. (2012). Mental accounting and false reference points in real estate investment decision making. Journal of Behavioral Finance, 13, 17-26.

Shin, H. B. (2009). Life in the shadow of mega-events: Beijing Summer Olympiad and its impact on housing. Journal of Asian Public Policy, 2, 122-141.

Shin, H. B., \& Li, B. (2013). Whose games? The costs of being "Olympic citizens" in Beijing. Journal of Environment and Urbanization. 25, 1-18.

Smith, A \& Fox, T. (2007). 'From 'Event-led' to 'Event-themed' Regeneration: the 2002 commonwealth games legacy programme. Urban Studies, 44, 1125-1143.

Smith, A. (2009). Theorising the relationship between major sport events and social sustainability. Journal of Sport and Tourism, 14, 109-120.

Smith A, (2012). Events and urban regeneration: The strategic use of events to revitalise cities. Routledge. London.

Soutar, G. N., \& McLeod, P. B. (1993). Residents' perceptions on impact of the America's cup.' 
Annals of Tourism Research, 20, 571-582.

Stovel, K. \& Bolan, M. (2004). Residential trajectories: Using optimal alignment to reveal the structure of residential mobility. Sociological Methods and Research, 32, 559-598.

Tower-Richardi, S. M., Brunyé, T. T., Gagnon, S. A., Mahoney, C. R. \& Taylor, H. A. (2014). Living the high life: social status influences real estate decision making. Joumal of Applied Social Psychology, 44, 611-621.

Wei, Y. D., \& Yu, D. (2006). State policy and the globalization of Beijing: emerging themes. Habitat International, 30, 377-395

Whitson, D., \& Horne, J. (2006). Underestimated costs and overestimated benefits? Comparing the outcomes of sports mega-events in Canada and Japan. The Sociological Review, 54, 7189.

Wu, W. J., Dong, G. P., 2014. Valuing the "Green" Amenities in a Spatial Context. Journal of Regional Science, 54, 569-585

Wicker, P., Prinz, J., \& Hanau, T. (2011). Estimating the value of national sporting success. Sport Management Review, 15, 200-210.

Yu, L., \& Cai, L. (2013). Challenges for housing rural-to-urban migrants in Beijing. Habitat International, 40, 268-277.

Zheng, S. Q., Sun, W. Z., Wang, R., 2014. Land supply and capitalization of public goods in housing prices: Evidence from Beijing. Joumal of Regional Science, 54, 550-568.

Zhou, Y., \& Ap, J. (2009). Resident perceptions towards the impacts of the Beijing 2008 Olympic Games. Journal of Travel Research, 48, 78-91.

Zou, Y. (2014). Contradictions in China's affordable housing policy: Goals vs. structure. Habitat International, 41, 8-16. 